\title{
Çocuklarda Tularemi: Tularemili 15 Olgunun Klinik, Laboratuvar ve Tedavi Sonuçlarının Değerlendirilmesi
}

\author{
Tularemia in Children: Evaluation of Clinical, Laboratory and Treatment \\ Outcomes of 15 Tularemia Cases
}

\section{Solmaz Çelebi, Ekrem Koyuncu, Şefika Elmas Bozdemir, Benhur Şirvan Çetin, Mustafa Kemal Hacımustafaoğlu}

Uludağ Üniversitesi Tıp Fakültesi Çocuk Sağlığı ve Hastalıkları Anabilim Dalı,Çocuk Enfeksiyon Bilim Dalı, Bursa, Türkiye

Yazışma Adresi/Address for Correspondence Dr. Solmaz Çelebi, Uludağ Üniversitesi Tıp Fakültesi Çocuk Sağlığı ve Hastalıkları Anabilim Dalı,Çocuk Enfeksiyon Bilim Dalı, Bursa, Türkiye Tel.: +90224 2950425 E-posta:solmaz@uludag.edu.tr

Geliş Tarihi/Received: 04.02.2013 Kabul Tarihi/Accepted: 12.03.2013

(c) Güncel Pediatri Dergisi, Galenos Yayınevi tarafindan basilmıştir.

(c) The Journal of Current Pediatrics, published by Galenos Publishing.

\section{ÖZET}

Giriş: Tularemi Francisella tularensis'in neden olduğu zoonotik hastalıktır. Bu çalışmanın amacı tularemi tanısı konan 15 çocuk olgunun klinik ve laboratuvar bulgularının değerlendirilmesidir. Gereç ve Yöntem: Çocuk Enfeksiyon Hastalıkları Polikliniğine ateş, boğaz ağrısı ve lenfadenopati (LAP) yakınması ile başvurup mikroaglütinasyon test (MAT) titresi 1/160 ve üstünde olan 15 olgu geriye dönük olarak değerlendirilerek sosyo-demografik özellikleri, hayvan ile temas ve kene ısırı̆ı öyküleri, yakınma süreleri, klinik ve laboratuvar bulguları, tedavileri ve klinik gidişleri incelendi.

Bulgular: Olguların yaş ortalaması $11,5 \pm 5,1$ yıl (3-17) ve \%53'ü erkek idi. Olguların \%53,3'ü kırsal kesimde yaşıyor ve kuyu suyu kullanıyordu. En sık başvuru yakınmaları olan boyunda şişlik $(\% 93,3)$, boğaz ağrısı $(\% 66,7)$ ve ateş yüksekliği $(\% 66,7)$ idi. Olgularda en sık orofarengeal tularemi $(\% 66,7)$ saptandı. Cerrahi olarak olguların \%27'sinin LAP'si boşaltılırken, $\% 13,3$ 'ünde ise LAP kendi kendine drene olmuştu. Bulgular başladıktan sonraki ortalama başvuru süresi 53 $\pm 45,3$ (5-150) gün bulundu. Başvuru öncesi olguların \%60'ında betalaktam grubu antibiyotik alımı vardı. Lenf bezleri süpüre olan 6 olgunun başvuru ortancası 61 (20150)gün, diğerlerinin ise 35 (5-75) gün olarak saptandı $p<0,05$. Laboratuvar incelemelerinde; lökosit sayısı 8558,6 $\pm 1384,5(6030-11400) / \mathrm{mm}^{3}$, CRP düzeyi 5,8 $\pm 2,9$ (1-6,7) mg/dl, ESH $33,1 \pm 28,9(6-103) \mathrm{mm} / \mathrm{saat}$ olarak bulundu. MAT titreleri 1/160 ile 1/1280 arasında idi. Yedi (\%47) olguya gentamisin, beş olguya (\%33) streptomisin, üç olguya (\%20) doksisiklin tedavisi uygulandl.

Sonuç: Tularemi, kırsal alanda yaşayan ve beta-laktam antibiyotiklere yanıt vermeyen tonsilofarenjit ve servikal LAP'Iı olgularda ayıııcı tanıda düşünülmelidir. (Güncel Pediatri 2013; 11: 57-62)

Anahtar kelimeler: Francisella tularensis, tularemi, çocuk

\section{SUMMARY}

Introduction: Tularemia is a zoonotic diseases caused by Francisella tularensis. The aim of this study was to evaluate the clinical and laboratory findings of 15 children with the diagnosis of tularemia.

Materials and Methods: Fifteen cases admitted with fever, sore throat, lymphadenopathy and a F. tularensis antibody titer of 1/160 and above in the microagglutination test (MAT) were evaluated retrospectively. Their sociodemographic characteristics, contact with animals, history of tick bite, duration of complaints, clinical and laboratory findings, treatments and clinical courses were studied.

Results: The mean age of patients was $11.5 \pm 5.1$ (3-17) years and $61.3 \%$ were male. Fiftythree percent of the patients were living in rural areas, and had contact with contaminated water. Swelling in the neck (93.3\%), sore throat $(66.7 \%)$ and fever $(66.7 \%)$ were the most frequently observed symptoms. Oropharyngeal tularemia $(66.7 \%)$ was predominated. In $27 \%$ of the patients LAPs were drained surgically, and in $13.3 \%$ of cases they were drained by itself. The mean duration between onset of tularemia symptoms and diagnosis was $53 \pm 45.3$ (5150 ) days. Sixty percent of patients were received beta-lactam-antibiotics before admission. 
It was noted that 6 patients with suppurative lymph nodes were admitted to hospital within median 61 (20-150) days, while others were admitted within median $35(5-75)$ days $(p<0.05)$. Mean leukocyte count was $8558.6 \pm 1384.5(6030-11400) / \mathrm{mm}^{3}$, mean CRP was $5.8 \pm 2.9$ (1-6.7) $\mathrm{mg} / \mathrm{dl}$, and mean ESR was $33.1 \pm 28.9$ (6-103) $\mathrm{mm} / \mathrm{h}$. MAT showed that titers ranged from 1/160 to 1/1280. Gentamicin was given in seven patients (47\%), streptomycin in five patients (33\%), and doxycycline in 3 patients (20\%).

Conclusions: Tularemia should to be taken into account in the differential diagnosis in patients having tonsillopharyngitis and cervical lymphadenopathy without response to beta-lactam antibiotics in rural areas. (Journal of Current Pediatrics 2013; 11: 61-6)

Key words: Francisella tularensis, tularemia, child

\section{Giriş}

Tularemi gram negatif, hareketsiz, aerob kokobasil olan Francisella tularensis'in neden olduğu bir zoonotik enfeksiyon hastalığıdır $(1,2)$. F. tularensis türünün dört farklı alt türü bulunmaktadır. Tip A F. tularensis spp. tularensis yüksek virulansa sahiptir ve ağır hastalığa neden olmaktadır. Keneler ve tavşanlarla bulaş olur. Vektör olarak sivrisinek, tatarcık ve böcekler de bulaşda önemlidir $(3,4)$. Tip B F. tularensis spp. palaerctica daha az virülandır, suyla ve kontamine olmuş besinlerle bulaşır $(1,3)$. F. tularensis spp. mediaasiatica sadece Orta Asya'da gösterilmiştir ve nadiren insan ve hayvanlarda hastalığa neden olur. Insanlarda ender olarak hastalık yapan F. tularensis spp. novicida ise az sayıda Kuzey Amerika'da bildirilmiştir $(4,5)$. Ülkemizde virülansı daha düșük olan F. tularensis spp. holarctica sonucu gelișen enfeksiyonlar bildirilmektedir (6). Ülkemizde son yıllarda yaşanan salgınların kaynağı olarak sular bildirilmektedir, kene ile kontaminasyon nadiren bildirilmiştir $(7,8)$. Etkenin virülansına, giriş yerine ve konakçının bağışıklık sistemine göre hastalığın 6 klinik formu vardır. Bunlar ülseroglandüler, glandüler, orofarengeal, oküloglandüler, tifoidal ve pulmoner formlardır $(2,9)$. Avrupa'da en sık görülen form ülseroglandüler form iken, Türkiye'de ise su kaynaklı salgınların bildirilmesi ile orofarengeal form en sık görülen formdur $(6,7,10)$. Bu çalışmanın amacı çocukluk yaş grubunda tularemi tanısı alan olguların klinik ve tedavi açısından değerlendirilmesidir.

\section{Gereç ve Yöntemler}

Çocuk Enfeksiyon Hastalıkları Polikliniğinde, 20092012 tarihleri arasında tularemi tanısı ile ayaktan tedavi gören olgular geriye dönük olarak değerlendirildi. Olguların sosyodemografik özellikleri, hayvan ile temas ve kene ısıı̆ğı öyküleri, başvuru öncesi yakınmaları, klinik ve laboratuvar bulguları, tedavileri ve klinik sonuçları değerlendirildi. Tularemi tanısı, uyumlu klinik ve epidemiyolojik bulguların olması ve serum mikroaglütinasyon testinin (MAT) pozitif saptanması ( $\geq 1 / 160)$ veya $7-10$ gün sonra alınan ikinci serum örneğinde tularemi aglütinasyon titresinin 4 kat artması ile konuldu. Orofarengeal tularemi epidemiyolojik bölgeden gelen; betalaktam/makrolid antibiyotiklere yanıt vermeyen veya bu antibiyotikleri alırken semptomlarında ilerleme olan; ateş, farenjit veya tonsillit ve/veya lenfadenopatisi (LAP) olan ve pozitif laboratuvar sonuçları olan hastalarda tanımlandı. Glandüler tularemi, ateş ve/veya LAP'ı olan ve serolojik olarak pozitif saptanan olgularda tanımlandı. Konjonktivit ve preauriküler LAP'ı olan hastalar ise oküloglandüler tularemi olarak kabul edildi. Hastaların başvurusunda tam kan sayımı, eritrosit sedimentasyon hızı (ESH) ve C-reaktif protein (CRP) değerleri ölçüldü. Mikroaglütinasyon testi Uludağ Üniversitesi Tıp Fakültesi Mikrobiyoloji Laboratuvarında çalışıldı. F. tularensis antikor titresinin $1 / 160$ ve üstünde olması pozitif olarak kabul edildi (2,9). Ultrasonografik olarak LAP'ın yerleşim yeri, en büyük LAP'ın uzun eksen ölçümü (mm), LAP içindeki nekroz ve apse formasyonu değerlendirildi. Semptom ve bulguları düzelen ve tutulmuş lenf bezleri süpürasyon olmadan iyileşen hastalarda, tedavi başarılı olarak kabul edildi. Tutulan lenf bezinde tedavi süresince veya sonrasında süpürasyon olması, tutulmuş lenf bezi boyutlarında artış veya yeni LAP saptanması ise tedavi başarısızlığı olarak kabul edildi. Tıbbi tedaviye yanıtsız hastalara cerrahi tedavi uygulandı. Bu hastalara eşlik edebilen eritema nodosum, çoğunlukla alt ekstremitelerin ekstansör yüzünde eritematöz gergin nodül ve plakların aniden ortaya çıkması ile karakterize birçok uyaranla tetiklenen kutanöz reaktif bir pannikülit olarak tanımlandı. Olgulara gentamisin $(7$ mg/kg/gün, 2 dozda, im), streptomisin (15 mg/kg/gün, 2 dozda, im) ya da doksisiklin (5 mg/kg/gün, 2 dozda, oral) tedavileri verildi. Tularemi tedavisi 10 güne tamamland. Cerrahi olarak çıkarılan doku örneği histokimyasal olarak uygulanan PAS ve Ziehl-Neelsen boyaları ile incelendi.

Çalışmada elde edilen tüm verilerin istatistik analizinde "SPSS for Windows Version 15.0" (SPSS Inc., Chicago, IL, USA) programı kullanıldı. Istatistiksel analizlerde MannWhitney U testi kullanıldı. Istatistiksel olarak anlamlı değer $p<0,05$ kabul edildi.

\section{Bulgular}

Hastaların ortalama yaşı $11,5 \pm 5,1$ (3-17) yıl ve \%53'ü erkek idi. Olguların sekizi $(\% 53,3)$ Bursa ya da Balıkesir'in köyünde yaşıyor ve içme suyu olarak kuyu suyu kullanıyordu. Kırsal kesimde yaşayan sekiz olgunun 







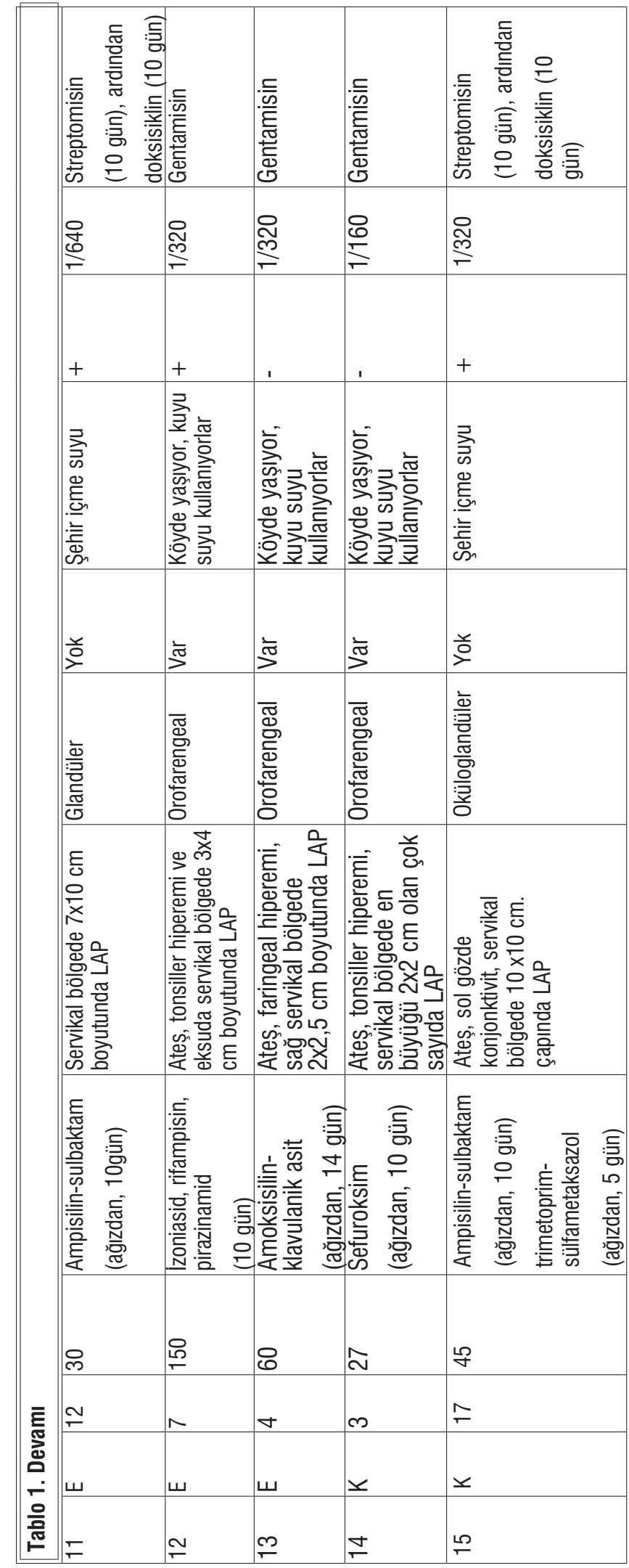

tamamında çevrede benzer hastalık öyküsü vardı. Hastaların hiçbirinde kene tutunması ve av hayvanı yeme gibi risk faktörleri yoktu. Tablo 1'de olguların demografik, klinik, laboratuvar ve tedaviye ilișkin özellikleri görülmektedir. En sık başvuru yakınmaları olan boyunda şişlik $14(\% 93,3)$ hastada, boğaz ağrısı $10(\% 66,7)$ hastada ve ateş $10(\% 66,7)$ hastada saptandı. Olgularda en sık orofarengeal form tularemi $(\% 66,7)$ saptandı. Glandüler tularemi olguların 4'ünde $(\% 26,7)$ mevcuttu. Lenfadenopatilerin tamamı servikal bölgede idi. Bir olguda $(\% 6,6)$ oküloglandüler tularemi saptandı. Orofarengeal tularemili bir olguda $(\% 6,6)$ ise alt ve üst ekstremitede yaygın eritema nodosum vardı. Olguların bulgular bașladıktan sonra ortalama başvuru süresi 53 $\pm 45,3$ (5-150) gün bulundu. Bașvuru öncesi olguların \%60'ında beta-laktam grubu antibiyotik alımı vardı. Lenf bezleri süpüre olan 6 olgunun başvuru ortancası 61 (20-150) gün, diğerlerinin ise 35 (575) gün olarak saptandı $(p<0.05)$. Laboratuvar incelemelerinde; ortalama periferik kan lökosit sayısı $8558,6 \pm 1384,5(6030-11400) / \mathrm{mm}^{3}$, ortalama CRP düzeyi $5,8 \pm 2,9(1-6,7) \mathrm{mg} / \mathrm{dl}$, ortalama $\mathrm{ESH}$ düzeyi $33,1 \pm 28,9$ (6-103) mm/saat olarak bulundu. Hastaların \%27'sinin LAP'ı Cerrahi olarak boşaltıldı, \%13,3'ünde ise LAP kendi kendine drene olmuştu. Tüberküloz lenfadenit düşünülen bir olguya terapötik amaçlı total eksizyonel lenf bezi biyopsisi uygulandı. Lenf bezinin histopatolojik incelemesinde nekrotizan granülamatöz enflamasyon varlığı ve MAT'ın pozitif saptanması ile tularemi tanısı kondu.

Yedi olguya (\%47) gentamisin, beş olguya (\%33) streptomisin ve üç olguya (\%20) doksisiklin tedavisi bașlandı. Gentamisin tedavisi başlanan iki olgunun $(\% 28,5)$ LAP'ında apseleşme olduğu için cerrahi drenaj uygulandı. Yine doksisiklin tedavisi alan bir olgunun $(\% 33,3)$ LAP'ında apseleşme olduğu için drenaj uygulandı ve tedavisi gentamisine değiștirildi. Streptomisin tedavisi başlanan iki olgunun (\%40) LAP'Inda apseleşme ve kendiliğinden drenaj olması nedeniyle tedavisi doksisikline değiştirildi. Olgularımızda mortalite gözlenmedi.

\section{Tartışma}

Tularemi, ülkemizde endemik bir hastalıktır. Türkiye'de ilk salgın 1936 yılında Trakya Bölgesinde bildirilmiş, ardından Marmara Bölgesi'nde ve farklı bölgelerden tularemi salgınları ve sporadik olgular ile ilgili yayınlar yapıımıştır (3,11-14). Tularemi etkeni sağlam deri ve müköz membranları geçebilir. Bulaşma sıklıkla cilt ve mukozal yüzeylerden, enfekte hayvan dokusu veya vücut sIVIsı ile temas sonrasında ya da enfekte tatarcık, kene veya sivrisinek tarafından Isırılmayı 
takiben olur. Nadiren de kontamine toz inhalasyonu, gıda ve suyun alınması ile bulaş olabildiği gibi laboratuar ortamında da olabilir, ancak organizma insandan insana bulaşmaz $(2,9)$. Türkiye'den bildirilen çalışmalarda su kaynaklı epidemiler görülmektedir $(15,16)$. Leblebicioğlu ve ark.'nın yaptıkları çalışmada çevreden toplanan yiyeceklerin ve su içilmesinin tularemi için risk faktörü olduğu bildirilmiştir (17). Bursa'nın bir köyünde tularemi epidemisi saptadığımı 10 olgunun değerlendirildiği çalıșmamızda, olguların tamamı orofarengeal tip olarak sınıflandırılmış ve kontamine su kaynaklı salgının geliştiği düşünülmüştür (11). Orofarengeal tularemide en sık semptomlar ateş, boğaz ağrısı ve servikal LAP'tır. Fizik incelemede sıklıkla tonsillitve/veya LAP görülür $(2,9)$. En sık başvuru yakınmaları, boyunda şişlik $(\% 93,3)$, boğaz ağrısı $(\% 66,7)$ ve ateş yüksekliği $(\% 66,7)$ idi. Ülkemizde yapılan çalışmalarda en sık olarak bildirilen orofarengeal formdur. Karadeniz ve Marmara Bölgelerinden yapılan çalışmalarda tüm olguların orofarengeal tularemi formunda olduğu bildirilmiştir $(15,18)$. Bursa ve civarında yapılan başka bir çalışmada 205 tularemi olgusunun \%83'ünün orofarengeal tularemi olduğu bildirilmiştir (3). Çalışmamızda 15 olgunun 10 'unda $(\% 66,7)$ orofarengeal tip tularemi saptanmıştır, 10 olgunun tamamı kırsal kesimde yaşamakta olup kontamine su kullanımı ve tamamının çevresinde benzer hastalık öyküsü vardı. Ülseroglandüler tularemi; dünyada en sık görülen klinik formdur, olguların \%7585 'inde görülür $(2,9)$. Olgularımızda ise ülseroglandüler form saptanmamıștır. Glandüler tularemide, ülser tespit edilmeden ateş yüksekliği ve LAP ile seyreden klinik mevcuttur. Olguların \%5-10'unda görülür. Çalışmamızda glandüler tularemi olguların 4'ünde $(\% 26,7)$ mevcuttu. Glandüler tutulumu olan olgularda kene ısııı̆ı ya da hayvan eti yeme öyküsü yoktu, tularemi kaynağı tespit edilemedi. Oküloglandüler tularemi nadir görülen tularemi tipi olup giriş yeri konjonktiva olarak kabul edilir. Enfekte hayvanlarla özellikle tavşanlarla temas sonrası el parmaklarının veya enfekte hayvanın vücut sıvılarının konjonktiva teması sonrasında, gözde enfeksiyon ve bölgesel LAP gelişir $(2,9)$. Çalışmamızda sadece bir olguda $(\% 6,6)$ oküloglandüler tularemi saptandı. Deri döküntüleri, tulareminin sık görülen komplikasyonlarından biri olup hastaların \%3-25'inde görülmektedir. Eritema nodosum ve eritema multiforme hastalığın seyri sırasında görülebilen deri bulgularıdır. Eritema nodosum benzeri deri lezyonları olan hastalarda deri lezyonu olmayan hastalara göre daha yüksek miktarda dolaşan poliklonal immünkompleksler bildirilmiştir (19). Bursa'da 205 tularemi olgusunun incelendiği bir çalışmada eritema multiforme benzeri cilt döküntüleri \%14 olarak belirtilmiştir (3). Evans ve arkadaşları 88 tularemili olguda $\% 4$ oranında eritema nodosum saptamışlardır (20). Daha önce yaptığımız bir çalışmada ise olguların \%40'ında eritema nodosum benzeri deri lezyonları saptanmıştı (11).
Bu çalışmada bir olgumuzda üst ve alt ekstremitede yaygın eritema nodosum lezyonları saptandı.

Olgularımızın \%66,7'si 10 yaşın üzerinde idi. Amerika Birleşik Devletleri'nde 10 yıllık tularemi olgularının değerlendiği bir çalışmada çocuk olguların \%75'inin 6 yaşından daha küçük olduğunu belirtmiştir (21). Önceki çalışmamızda olguların \%80'ni 10 yaş ve üzerinde idi (11). Sivas ve civarında 27 tularemili olgunun değerlendirildiği çalışmada olguların \%81,4'ünün 10 yaş ve üzerinde olduğu bildirilmiştir (22).

Tularemi seyri sırasında lökosit sayısı normal veya yüksek bulunabilir (2). Tularemi olgularının incelendiği bir çalışmada ortalama periferik kan lökosit sayısı 10400/ mm3 olarak bildirilmiştir (23). Çalışmamızda hastaların başvurusundaki ortalama periferik kan lökosit sayısı $8558,6 \pm 1384,5 / \mathrm{mm} 3$ idi.

Tularemi kesin tanısı bakterinin çeşitli örneklerden izolasyonuyla konur. Ancak üretmek için özel besiyeri gerektiğinden tanı daha çok serolojik testler ile konur. Helvacı ve ark. yaptıkları çalışmada, hastaların \%4,9'unda bakterinin izole edildiği bildirilmiştir (3). Bevanger ve ark. ise 57 tularemili olgunun sadece birinde bakterinin saptandığını belirtmişlerdir (24). Tularemi tanısında en sık kullanılan yöntemler hasta serumunda antikor aramaya yönelik MAT, tüp aglütinasyonu, lateks aglütinasyonu ve ELISA'dır. Tek bir serum örneğinde MAT'ın $\geq 1 / 160$ olması pozitif olarak kabul edilmektedir (16). Çalışmamızda etken izole edilemedi, tanı klinik bulgular ve MAT pozitifliği ile kondu.

Tularemi tedavisinde streptomisin, gentamisin ve doksisiklin önerilmektedir $(2,9,25)$. Tedaviye $7-10$ gün devam edilir. Daha hafif olgularda siprofloksazin alternatif tedavi olabilir (26). Beta-laktam grubu antibiyotikler, makrolidler ve ko-trimoksazol tedavide etkisizdir. Bazı çalışmalarda tularemide tedavi başarısızlığının nedeni tularemi tedavisinin geç başlanması, altta yatan kronik hastalığın olması, tedavi öncesinde fluktuasyon veren LAP'In olması olarak belirtilmiştir $(27,28)$. Çalışmamızda olguların ortalama başvuru süresi $53 \pm 45,3 \quad(5-150)$ gün olup başvuru öncesi \%60'ında beta-laktam grubu antibiyotik alımı vardı. Gentamisin tedavisi alan 2 olguya $(\% 28,5)$ cerrahi drenaj uygulandı. Lenf nodunda apseleşme olan ve doksisiklin alan olgunun tedavisi gentamisine, streptomisin alan iki olgunun tedavisi doksisikline değiştirildi. Çocuklarda yapılan bir çalışmada gentamisin tedavisine cevapsızlık oranı $\% 37,5$ olarak bildirilmiştir (29). Jounio ve ark. tularemili 50 çocuk olgunun dördünde lenf bezinde süpürasyon geliştiğini saptamışlar ve bulgular ile tedaviye başlama arasındaki sürenin bir aydan daha uzun olan olgularda apseleşmenin daha fazla geliştiğini bildirmişlerdir (30). Çalışmamızda lenf bezinde apseleşme olan 6 olgunun başvuru ortancası 61 (20-150) gün, diğerlerinin ise 35 (5-75) gün olarak 
bulundu, lenf bezinde apseleșme olan olguların hastaneye daha geç başvurdukları saptandı.

Lenfadenit nedeniyle başvuran olguların öyküsünde çevrede benzer hastaların varlığı ile tularemiden erken dönemde kuşkulanıp mikroagglütinasyon testinin yapılması enfeksiyonun kontrolünde önemli olacaktır. Tularemide erken tanı ve uygun tedavi ile komplikasyonlar önlenebilecektir.

\section{Kaynaklar}

1. Ellis J, Oyston PC, Green M, Titball RW. Tularemia. Clin Microbiol Rev 2002;15:631-46.

2. Penn RL. Francisella Tularensis (Tularemia). In: Mandell GL, Douglas RG, Bennett JE (eds). Mandell, Dougles, and Bennett's Principles and Practice of Infectious Diseases. 7th ed. New York: Churchill Livingstone; 2010. p. 2927-37.

3. Helvaci S, Gedikoğlu S, Akalin H, Oral HB. Tularemia in Bursa, Turkey: 205 cases in ten years. Eur J Epidemiol 2000;16:271-6.

4. Christova I, Velinov T, Kantardjiev T, Galev A. Tularaemia outbreak in Bulgaria. Scand J Infect Dis 2004;36:785-9.

5. Bıçakçı Z, Öztürk B. The Contamination of tuleramia from the saliva of cow to a two year-old boy: case report by long-term observation. J Child 2008;8:197-9.

6. Gürcan S. Francisella tularensis and tularemia in Turkey. Mikrobiyol Bul 2007;41:621-36.

7. KIlıç S. Francisella tularensis ve Türkiye'de tularemi epidemiyolojisine genel bir bakış. Flora 2010;15:37-58.

8. Yeşilyurt M, Kllıc S, Çağaşar Ö, Çelebi B, Gül S. Yozgat ilinde kene kaynaklı iki tularemi olgusu. Mikrobiyol Bul 2011;45:74654.

9. Schutze GE, Jacobs RF. Tularemia (Francisella tularensis). In: Kliegman RM, Stanton BF, Geme JW, Schor NF, Behrman RE, eds. Nelson Text Book of Pediatrics. 19th ed. Philadelphia: Elsevier Saunders; 2011. p. 978-80.

10. Ulu KIlıç $A$, Kilıç $S$, Sencan I, Ciçek Şentürk G, Gürbüz Y, Tütüncü EE, et al. A water-borne tularemia outbreak caused by Francisella tularensis subspecies holarctica in Central Anatolia region. Mikrobiyol Bul 2011;45:234-47.

11. Celebi S, Hacimustafaoglu M, Gedikoglu S. Tularemia in children. Indian J Pediatr 2008;75:1129-32.

12. Ozdemir D, Sencan I, Annakkaya AN, Karadenizli A, Guclu E, Sert E, et al. Comparison of the 2000 and 2005 outbreaks of tularemia in the Duzce region of Turkey. Jpn J Infect Dis 2007;60:51-2.

13. Gurcan S, Eskiocak M, Varol G, Uzun C, Tatman-Otkun M, Sakru N, et al. Tularemia reemerging in European part of Turkey after 60 years. Jpn J Infect Dis 2006;59:391-3.

14. Celebi G, Baruönü F, Ayoğlu F, Cinar F, Karadenizli $A$, Uğur $M B$,et al. Tularemia, a reemerging disease in northwest Turkey: epidemiological investigation and evaluation of treatment responses. Jpn J Infect Dis 2006;59:229-34.
15. Tatman Otkun M, Akçalı A, Karadenizli A, Ozbey N, Gazel D, Sener A, et al. Çanakkale'de hızla önlenen bir tularemi salgınının epidemiyolojik olarak değerlendirilmesi. Mikrobiyol Bul 2011;45:48-57

16. Meric M, Sayan M, Dundar D, Willke A. Tularaemia outbreaks in Sakarya, Turkey: case-control and environmental studies. Singapore Med J 2010;51:655-9.

17. Leblebicioglu H, Esen S, Turan D, Tanyeri Y, Karadenizli A, Ziyagil F, et al. Outbreak of tularemia: a case-control study and environmental investigation in Turkey. Int $\mathrm{J}$ Infect Dis 2008;12:265-9.

18. Acicbe Ö, Aydın H, Doğancı L. Endemic of Tularemia in HavzaSamsun Region: A Retrospective Evaluation of the Cases. Infeksiyon Dergisi 2007;21:55-8.

19. Akdiş AC, Kilicturgay K, Helvaci S, Mistik R, Oral B. Immunological evaluotion of erythema nodosum in tularemia. Br J Dermatol 1993;129:275-9.

20. Evans ME, Gregory DW, Schaffner W, McGee ZA. Tularemia: a 30-year experience with 88 cases. Medicine (Baltimore) 1985;64:251-69.

21. Snowden J, Stovall S. Tularemia: retrospective review of 10 years' experience in Arkansas. Clin Pediatr (Phila) 2011;50:648.

22. Kaya A, Deveci K, Uysal IO, Güven AS, Demir M, Uysal EB, et al. Tularemia in children: evaluation of clinical, laboratory and therapeutic features of 27 tularemia cases. Turk J Pediatr 2012;54:105-12.

23. Syrjala H. Peripheral blood leukocyte counts, erytrocyte sedimentation rate and C-reactive protein in tularemia caused by the type $B$ strain of Francisella tularensis. Infection 1986;14:51-4.

24. Bevanger I, Maeland JA, Naess Al. Agglutinins and antibodies to Francisella tularensis outer membrane antigens in the early diagnosis of disease during an outbreak of tularemia. J Clin Microbiol 1988;26:433-7.

25. Schell 0, Reiersen R, Hoel T. Treatment of tularemia with ciprofloxacin. Eur J Clin Microbiol Infect Dis 1992;11:447-8.

26. World Health Organization (WHO). WHO Guidelines on tularaemia. Geneva: World Health Organization; 2007. WHO/CDS/EPR/2007.7. (http://whqlibdoc. who.int/ publications/2007/9789241547376_eng.pdf. Erişim tarihi 12.11.12012.

27. Risi GF, Pomo DJ. Relaps of tularemia after aminoglycoside therapy: case report and discussion of therapeutic options. Clin Infect Dis 1995;20:174-5.

28. Penn RL, Kinasewitz GT. Factors associated with a poor outcome in tularemia. Arch Intern Med 1987;147:265-8.

29. Önen S, Paksoy D, Bilge YD. Çocukluk çağında tularemi olguları. J Pediatr Inf 2012;6:94-100.

30. Jounio U, Renko M, Uhari M. An outbreak of holarcticatype tularemia in pediatric patients. Pediatr Infect Dis $\mathrm{J}$ 2010;29:160-2. 